\title{
Rifampicin-resistant Mycobacterium leprae in an elderly leprosy patient in the People's Republic of China
}

\author{
Meiwen $\mathrm{Yu}^{1, *}$ \\ Kan Wu ${ }^{1, *}$ \\ Bing Pei ${ }^{2}$ \\ Degang Yang ${ }^{2}$ \\ Qiulin Wang' \\ Hongsheng Wang' \\ Jianping Shen' \\ Liangbing Yan' \\ Guochen Zhang' \\ 'Institute of Dermatology, Chinese \\ Academy of Medical Sciences and \\ Peking Union Medical College, \\ National Center for STD and \\ Leprosy Control, China CDC, \\ Nanjing, People's Republic of China; \\ ${ }^{2}$ Department of Infectious Diseases, \\ Shanghai Skin Disease Hospital, \\ Shanghai, People's Republic of China \\ *These authors contributed equally \\ to this work
}

This article was published in the following Dove Press journal:

Clinical Interventions in Aging

20 August 2013

Number of times this article has been viewed

\begin{abstract}
The reported number of registered leprosy patients worldwide declined with the introduction of multidrug therapy. However, the emergence of rifampicin resistance in leprosy patients engenders difficulties for an individual patient, and its dissemination could pose a threat to leprosy control. This study reports an elderly patient who was diagnosed with rifampicinresistant lepromatous leprosy. This case indicates that inadequate treatment and poor compliance may eventually result in rifampicin resistance in Mycobacterium leprae and clinical relapse.
\end{abstract}

Keywords: leprosy, rifampicin, drug resistance, elderly patient

\section{Introduction}

Rifampicin (RFP) is a highly effective antibiotic against most Gram-positive bacteria as well as many other Gram-negative microorganisms. It is more effective against Mycobacterium leprae than any other prescribed anti-leprosy drug and is considered the core of multidrug therapy (MDT) for leprosy. RFP can eradicate $99 \%$ of the bacteria present within days in a single dose. However, resistance can develop rapidly in vitro as a one-step process. One in every $10^{7}-10^{8}$ tubercle bacilli is estimated to be resistant to RFP. ${ }^{1}$ The use of RFP against $M$. leprae started later than dapsone (DDS) and reports of the resistance cases began to appear in 1976 and onwards. ${ }^{2}$ Improper use of drugs, such as monotherapy and inadequate treatment, frequently lead to drug resistance, which threatens the usefulness of the compounds in antibiotic therapy. To date, no RFP-resistant $M$. leprae strain has ever been isolated from a Chinese leprosy patient treated with MDT.

\section{Case report}

A 66-year-old male Chinese leprosy patient was referred to the authors' hospital for investigation as a suspected case of drug-resistant $M$. leprae caused by inadequate treatment, poor compliance, and clinical relapse. The patient was diagnosed with lepromatous leprosy at the age of 46 years and treated with DDS $50 \mathrm{mg} /$ day. He stopped taking pills half a year later when the skin lesions had cleared. However, the patient continued experiencing progressive and worsening numbness of the limbs for the next 18 years, during which he was out of medical record and took alternative medicine instead. In April 2009, the patient sought medical help from a private practitioner for itchy rashes on his abdomen, buttocks, and groin. He was prescribed isoniazid, RFP, and DDS, but the patient only took RFP irregularly. An initial response to treatment was observed, but new nodules and ulcers soon developed all over the patient's body.
Correspondence: Hongsheng Wang Institute of Dermatology, Chinese Academy of Medical Sciences and Peking Union Medical College, National Center for STD and Leprosy Control, China CDC, 12 Jiangwangmiao Street, Nanjing 210042, People's Republic of China

Tel +86 2585478953

Fax +86 25 854I 4477

Email wanghs@ncstdlc.org 
On July 4, 2011, the patient was finally admitted and smears showing a bacillary index of 5.0 were taken. He was diagnosed with relapsed lepromatous leprosy with possible RFP resistance.

Acid-fast bacilli were isolated from a skin biopsy specimen (Figure 1A). Identification of the isolate by polymerase chain reaction and gene sequencing of $M$. leprae-specific repetitive element and $16 \mathrm{~S}$ rDNA genes was carried out. ${ }^{3,4}$ The sequence analysis of $M$. leprae-specific repetitive element and $16 \mathrm{~S}$ rDNA genes showed $100 \%$ similarity with $M$. leprae. Amplification and DNA sequencing of folP1, rpoB, and gyrA genes - involved in resistance to DDS, RFP, and quinolones, respectively - were also performed (Figure 1C). ${ }^{5}$ Sequence analysis of these genes revealed a mutation within codon 441 of the $r p o B$ gene (GAT $\rightarrow$ AAC), which indicates that it is the third reported strain harboring this mutation but a new two-base substitution (Figure 1D). No mutation of folP1 or gyrA gene was found in this strain. The sequences were analyzed with the BLAST ${ }^{\circledR}$ version 2.0 software (National
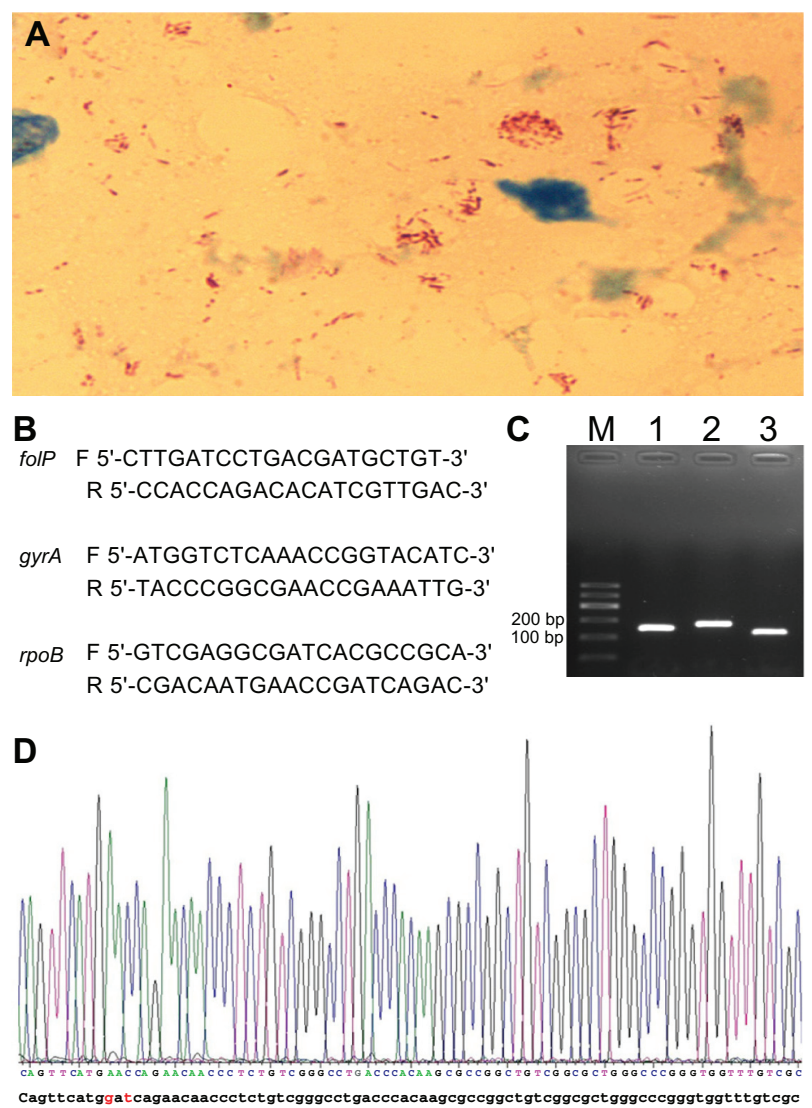

Figure I (A) Microscopic observation of numerous acid fast bacilli (red rods) in the slit skin smear fluid from a solitary lesion in the face at the initial presentation of the patient. Original magnification: $\times I, 000$. (B) Primers used in this study. The letters $F$ and $\mathrm{R}$ refer to forward and reverse primer, respectively. (C) Amplification products of folP, gyrA, and rpoB genes (lanes I-3, respectively). (D) A mutation of codon 44I of the $r$ o $B$ gene was found (GAT $\rightarrow A A C$ ) (indicated in red).
Library of Medicine, Bethesda, MD, USA), available at http:// www.ncbi.nlm.nih.gov/BLAST/.

A regimen including $500 \mathrm{mg}$ clarithromycin twice daily, $400 \mathrm{mg}$ moxifloxacin once daily, $100 \mathrm{mg}$ DDS once daily, and $50 \mathrm{mg}$ clofazimine once daily was prescribed. The patient attended regularly for 3 months and then was lost. On his last visit, observations showed that the skin lesions of the patient had gradually subsided and that his bacillary index had dropped to 3.2 .

\section{Conclusion}

About 62 RFP-resistant strains of $M$. leprae and 102 nucleotide mutations have been reported. ${ }^{6-12}$ Codon 441 of the rpoB gene is the fourth most frequently detected mutated site in RFP-resistant strains, following codons 456, 451, and 481. The authors considered this case to be a case of secondary resistance because of the lack of reports on primary RFP resistance in the People's Republic of China. The patient's improper use of RFP may have led to the development of resistant mutants overgrowing wild strains.

While the bacteria isolated from the patient is the first RFP-resistant $M$. leprae strain detected in the People's Republic of China, the actual number of strains showing such resistance may be higher than currently known, mainly because of limited awareness and access to testing facilities. This issue is worth considering because concerns about the higher resistance rate of $M$. leprae to RFP than DDS in the post-MDT era have increased, although such concerns may be biased self-reported cases. ${ }^{5}$

MDT significantly shortens the course of DDS monotherapy by reducing the emergence of DDS-resistant strains. Improper use of RFP leads to resistance, which requires less time to develop than DDS resistance. The authors were not surprised that the patient opted to be treated with only RFP. Because of a lack of medical resources, patients from the remote underdeveloped countryside are prone to visit private doctors first instead of formal health facilities. RFP is the only effective drug they are able to easily acquire; DDS and clofazimine are administered free of charge but these are only available in local public hospitals where patients are reluctant to visit and afraid of spending too much time at. Fear of the harmless "red urine" caused by RFP and belief in alternative medicines are not uncommon among elderly patients in the People's Republic of China. This scenario makes regular monotherapy, not to mention full-length MDT, nearly impossible. Unfortunately, prolonged inadequate treatment and poor compliance may eventually result in drug resistance. Resistance is a serious problem that must be addressed to 
prevent new resistant cases where patients become sources of infection. An approach that may be utilized to address drug resistance involves the use of molecular biological assays to confirm suspected drug resistance cases and select alternative drugs with which to treat persistent pathogens. To accomplish such an endeavor, the effort of medical workers, financial support, and public health awareness are necessary.

For this particular patient, the authors believe that both RFP resistance and a senile degenerated immune system contributed to the fluctuations observed during the long course of the disease. Switching anti-leprosy drugs, which was generally well-tolerated by the patient, resulted in a favorable response during the first 3 months of treatment. However, the authors doubt that the patient will continue with his regimen because clarithromycin and moxifloxacin are much more expensive than RFP and they are not covered by such a program. Allowing access to these drugs in the countryside is also a problem. A previous study demonstrated that RFP-resistant strains show growth disadvantages and lower virulence compared with RFP-susceptible Staphylococcus aureus. If the patient returns for follow up, investigating the changes in microbial flora at the molecular level and associating it with compliance in drug intake will be of great interest.

\section{Acknowledgments}

This study was supported by grants from the National Natural Science Foundation of China (Number 30972651) and a fund from the Key Clinical Program of the Ministry of Health (Number 2010-2012-125).

\section{Disclosure}

The authors report no conflicts of interest in this work.

\section{References}

1. Tsukamura M. The pattern of resistance development to rifampicin in Mycobacterium tuberculosis. Tubercle. 1972;53(2):111-117.

2. Jacobson RR, Hastings RC. Rifampin-resistant leprosy. Lancet. 1976;2(7998):1304-1305.

3. Truman RW, Andrews PK, Robbins NY, Adams LB, Krahenbuhl JL, Gillis TP. Enumeration of Mycobacterium leprae using real-time PCR. PLoS Negl Trop Dis. 2008;2(11):e328.

4. Kirschner P, Bottger EC. Species identification of mycobacteria using rDNA sequencing. Methods Mol Biol. 1998;101:349-361.

5. Gupta UD, Katoch K, Katoch VM. Study of rifampicin resistance and comparison of dapsone resistance of M. leprae in pre- and post-MDT era. Indian J Lepr. 2009;81(3):131-134.

6. Maeda S, Matsuoka M, Nakata N, et al. Multidrug resistant Mycobacterium leprae from patients with leprosy. Antimicrob Agents Chemother. 2001;45(12):3635-3639.

7. Honore N, Cole ST. Molecular basis of rifampin resistance in Mycobacterium leprae. Antimicrob Agents Chemother. 1993;37:414-418.

8. Kim SO, Kim MJ, Chae GT, Suh JW. Detection of rifampin resistance mutation and its altered nucleotide sequences in Mycobacterium leprae isolated from Korean patients with leprosy. J Microbiol. 1996;34(3): 236-240.

9. Cambau E, Perani E, Guillemin I, Jamet P, Ji B. Multidrug-resistance to dapsone, rifampicin, and ofloxacin in Mycobacterium leprae. Lancet. 1997;349(9045):103-104.

10. Moorman DR, Mandell GL. Characteristics of rifampin-resistant variants obtained from clinical isolates of Staphylococcus aureus. Antimicrob Agents Chemother. 1981;20(6):709-713.

11. Cambau E, Bonnafous P, Perani E, Sougakoff W, Ji B, Jarlier V. Molecular detection of rifampin and ofloxacin resistance for patients who experience relapse of multibacillary leprosy. Clin Infect Dis. 2002;34(1):39-45.

12. You EY, Kang TJ, Kim SK, Lee SB, Chae GT. Mutations in genes related to drug resistance in Mycobacterium leprae isolates from leprosy patients in Korea. $J$ Infect. 2005;50(1):6-11.
Clinical Interventions in Aging

\section{Publish your work in this journal}

Clinical Interventions in Aging is an international, peer-reviewed journal focusing on evidence-based reports on the value or lack thereof of treatments intended to prevent or delay the onset of maladaptive correlates of aging in human beings. This journal is indexed on PubMed Central, MedLine, the American Chemical Society's 'Chemical Abstracts

\section{Dovepress}

Service' (CAS), Scopus and the Elsevier Bibliographic databases. The manuscript management system is completely online and includes a very quick and fair peer-review system, which is all easy to use. Visit http://www.dovepress.com/testimonials.php to read real quotes from published authors. 